\title{
Hahnemann's Closure as a Lesson in Private Equity Healthcare
}

\author{
Kevin D'Mello, MD, FACP, FHM
}

Department of Internal Medicine, Drexel University College of Medicine, Philadelphia, Pennsylvania (now with Cooper University Hospital, Camden, New Jersey).

rate

he recent closure of Hahnemann University Hospital, a 500-bed teaching hospital in downtown Philadelphia, Pennsylvania, offers a case study of a new form of for-profit business involvement in academic medicine - private equity investment. Though the closure of this 171-year-old institution is the result of multiple factors affecting the hospital's financial health over decades and may not have been avoidable, the hospital's final years in the hands of a private equity firm led to a closure process that was chaotic, uncoordinated, and fundamentally not aligned with the needs of the patients and trainees that make up the core constituents of a teaching hospital. This hospital's story involves a concerning trend that underscores the dissonance in mission of private equity and academic medicine. In an era of competition and market consolidation, other teaching hospitals may be forced to close under similar circumstances in the future, making it vital that the medical and academic communities be aware of these discordant missions to guide policy-making efforts and ensure that the needs of patients and trainees take priority in transition planning rather than the needs of investors.

Tracing the hospital's history, much of its financial troubles began over 20 years ago. In 1993, the Allegheny Health, Education, and Research Foundation (AHERF), a nonprofit Pittsburgh-based hospital and physician practice organization, acquired Hahnemann Medical College. Forming the MCPHahnemann Medical School, AHERF merged the institution with another acquisition, Medical College of Pennsylvania (MCP), ${ }^{1}$ formerly known as the Woman's Medical College of Pennsylvania, one of the first American medical schools devoted to exclusively training female physicians. ${ }^{1,2}$ This was part of AHERF's aggressive growth strategy at the time and resulted in the acquisition of 14 hospitals and more than 300 Philadelphia-area primary care physician practices by 1998 This caused about $\$ 1.3$ billion of debt and over $\$ 1$ million in losses per day, which led AHERF to file for bankruptcy that year, ${ }^{2}$ the country's largest nonprofit healthcare bankruptcy at the time. ${ }^{1}$ That same year, Tenet Healthcare Corporation, a for-profit healthcare company, bought AHERF's assets in the Philadelphia region from bankruptcy for $\$ 345$ million, acquiring eight hospitals, as well as all of AHREF's physician practices. ${ }^{2}$

Corresponding Author: Email: dmello-kevin@cooperhealth.edu.

Published online first February 19, 2020.

Received: August 28, 2019; Revised: December 23, 2019;

Accepted: January 3, 2020

๑) 2020 Society of Hospital Medicine DOI 10.12788/jhm.3378
Ultimately, Tenet sold or closed six of the acquired hospitals by 2007, leaving just Hahnemann and St. Christopher's Hospital for Children, ${ }^{3}$ while Drexel University, a private, nonprofit university, came forward to salvage AHERF's educational programs, creating the Drexel University College of Medicine. ${ }^{2}$ Under the ownership of Tenet, Hahnemann's financial health declined as its patient population included a growing proportion of those utilizing Medicare, Medicaid, and charity care, which resulted in a negative operating profit margin annually for the final 14 years under Tenet. ${ }^{3,4}$ In this setting, American Academic Health System, LLC (AAHS) stepped in to purchase Hahnemann and St. Christopher's from Tenet and, eventually, chose to close Hahnemann. ${ }^{4}$

That Hahnemann found itself in the hands of a private equity firm was not surprising. Such investment firms' acquisitions of hospitals and physician practices have become increasingly more common, with the number of these types of deals increasing by $48 \%$ and reaching a value of $\$ 42.6$ billion from 2010 to $2017 .{ }^{5}$ While for-profit hospitals have been shown to have higher mortality ${ }^{6}$ and lower patient satisfaction ${ }^{7}$ than nonprofit hospitals, the relatively new and growing trend of private equity investment in healthcare has not been rigorously evaluated. By nature, these firms use investor capital to acquire assets with the goal of increasing their value and selling them off at a profit after about 3-7 years. ${ }^{5}$ Thus, healthcare services provided by private equity-owned facilities are valued and supported based on their profitability. Low-profit services, such as primary care and psychiatry, are minimized while more profitable services, such as same-day surgery, are maximized. ${ }^{5}$ In addition, given that for-profit hospitals tend to invest less in charity care ${ }^{8}$ and population health 9 as compared with nonprofit institutions, private equity-owned hospitals likely follow suit, in contrast to the humanistic values of academic medicine. Ultimately, Hahnemann's decades-long financial troubles set the stage for a buyout by private equity investors. But this transaction was the death knell for this teaching hospital and eventually proved to be a disadvantage for the community it served.

Purchasing Hahnemann and St Christopher's from Tenet in early 2018 for $\$ 170$ million, AAHS-an affiliate of the private equity firm, Paladin Healthcare Capital, LLC, led by investment banker Joel Freedman-entered the Philadelphia healthcare market in partnership with Chicago-based healthcare real estate private equity firm, Harrison Street Real Estate Capital, LLC. ${ }^{4}$ Paladin had previously invested in smaller hospitals serving underserved communities, ${ }^{4}$ and as it began its venture with this large teaching hospital, Paladin's president, 
Barry Wolfman, stated that the company's goal was "to return [Hahnemann] to its rightful place in the landscape of healthcare. ${ }^{3}$ However, given the real estate firm's involvement in the deal and the permissive tier of zoning for Hahnemann's real estate ${ }^{10}$ there were suspicions that the purchase of the hospital was a means to acquire and develop the valuable Center City real estate rather than to serve the community. ${ }^{3}$

Within months of the hospital purchase, AAHS's Philadelphia venture proved difficult. Four CEOs came and went as time passed, with some holding their position for only a couple of months. ${ }^{11}$ About 175 of Hahnemann's nurses, support staff, and managers were laid off in April of 2019, but the hospital finances did not improve significantly. ${ }^{12}$ As it became evident that AAHS planned to close the hospital, efforts were made to prevent the closure. Drexel University filed an unsuccessful lawsuit, claiming that it would be a violation of the academic agreement between the university and hospital. ${ }^{13}$ Once AAHS announced plans for hospital closure, the Pennsylvania Secretary of Health, Rachel Levine, MD, wrote to AAHS leadership ordering a "cease and desist" of any action toward hospital closure. ${ }^{12}$ Despite this, AAHS began cutting vital hospital services, including trauma and cardiothoracic surgery services, within days of the closure announcement. ${ }^{14}$ While there is a state law that a hospital cannot be closed with less than 90 days' notice, AAHS filed for bankruptcy and shut down Hahnemann's service to the community in about half that time. ${ }^{13}$ The hospital real estate was separated from the operating businesses and was excluded from the bankruptcy filing, ${ }^{10}$ which further cemented suspicions that the involved private equity firms looked to profit off the land once the hospital closed.

The immediate and long-term effects of the closure of Hahnemann University Hospital on healthcare and medical education in Philadelphia are yet to be rigorously measured and evaluated. However, the hasty closure of a large inner-city teaching hospital that served as a healthcare safety net for a largely underserved minority population with 50,000 ED visits per year ${ }^{4}$ is a dangerous disruption to a community. The way that the hospital was closed not only defied regulatory attempts at protecting the community but also defied the values of the healthcare workers working in the hospital. Because AAHS ceased payments to hospital vendors, medical supplies were low during the final weeks at Hahnemann, which didn't even have enough cups on the wards to provide drinking water for patients. ${ }^{15}$ Nurses reported feeling shame as they used scissors to cut wash cloths in half to have enough to wash their patients..$^{15}$ The teaching hospital's humanistic and social capital was being liquidated quickly. Even after Hahnemann's 570 graduate medical trainees endured the stressful and chaotic process of being displaced and fortunately taken in by other programs, ${ }^{16} \mathrm{AAHS}$ attempted to auction off Hahnemann's graduate medical education (GME) slots and their associated government funding to the highest bidder. While a US bankruptcy judge initially approved the sale of those GME slots to a consortium of academic institutions in the Philadelphia area, ${ }^{17}$ the Center for Medicare \& Medicaid Services (CMS) has ap- pealed that decision, which resulted in a current stay on the transaction. ${ }^{17}$ AAHS treating GME trainee positions as assets to be bought and sold is a dangerous precedent to set, especially since it attempts to bypass CMS's existing regulated process for redistributing the slots.

While time will reveal the effects of the hospital closure, the most concerning element of this story is that the methods of a private equity firm in closing a large inner-city teaching hospital flouted attempts by regulatory agencies acting to preserve the hospital's mission to the community. The governor of Pennsylvania, Tom Wolf (D), and mayor of Philadelphia, Jim Kenney (D), issued a joint statement chastising the actions of AAHS: "The situation at Hahnemann University Hospital, caused by CEO Joel Freedman and his team of venture capitalists, is an absolute disgrace and shows a greed-driven lack of care for the community. ${ }^{18}$ This chaotic situation inspired Philadelphia Councilperson Helen Gym (D) to propose city legislation requiring 180 days' notice of a hospital closure, bestowing a strong local means of protecting the city's people from similar healthcare fiascos in the future. ${ }^{15}$

At its core, healthcare is a human-to-human interaction with the purpose of improving and maintaining the health and life of the patient. Adding to that the noble efforts in educating students and trainees to provide that public good, academic medicine is a virtuous endeavor. The new and growing phenomenon of private equity in healthcare prioritizes maximizing a return on investment, so the closure of Hahnemann University Hospital in Philadelphia highlights manifestations of the discordance of the missions of private equity and academic medicine and serves as "the canary in the coal mine," warning teaching hospitals and communities that this disconnect necessitates regulatory policies to protect academic medicine's service to the community while private equity investment continues to spread in healthcare.

Disclosures: The author has nothing to disclose.

\section{References}

1. Burling, S. Hahnemann University Hospital: 171 years of Philadelphia medical history. The Philadelphia Inquirer. https://www.inquirer.com/health/ hahnemann-university-hospital-timeline-history-20190821.html. August 21, 2019. Accessed October 10, 2019

2. Klasko $\mathrm{S}$ and Ekarius J. Collision course: The privatization of graduate medical education at one university. Acad Med. 2007;82(3):238-244. https://doi. org/10.1097/ACM.0b013e3180305fb1.

3. Brubaker H. Tenet will leave Philly, selling Hahnemann, St. Christopher's to Paladin. The Philadelphia Inquirer. https://www.inquirer.com/philly/business/ tenet-leaves-philly-selling-hahnemann-st-christophers-to-paladin-20170901. html. September 1, 2017. Accessed October 10, 2019.

4. Brubaker $\mathrm{H}$. This California banker bet on turning around Philly's Hahnemann Hospital. He's running out of time. The Philadelphia Inquirer. https://www. inquirer.com/business/hahnemann-turnaround-closure-california-banker-joel-freedman-20190408.html. April 8, 2019. Accessed October 10, 2019

5. Gondi $S$ and Song Z. Potential implications of private equity investments in health care delivery. JAMA. 2019;321(11):1047-1048. https://doi.org/10.1001/ jama.2019.1077

6. Devereaux PJ, Choi PT, Lacchetti $C$, et al. A systematic review and meta-analysis of studies comparing mortality rates of private for-profit and private notfor-profit hospitals. CMAJ. 2002;166(11):1399-1406.

7. Mazurenko O, Collum T, Ferdinand A, and Menachemi N. Predictors of hospital patient satisfaction as measured by HCAHPS: A systematic re- 
view. J of Healthc Manag. 2017;62(4):272-283. https://doi.org/10.1097/ JHM-D-15-00050.

8. Valdovinos E, Le S, Hsia RY. In California, not-for-profit hospitals spent more operating expenses on charity care than for-profit hospitals spent. Health Affairs. 2015;34(8):1296-1303. https://doi.org/10.1377/hlthaff.2014.1208.

9. Gabriel MH, Atkins D, Liu X, Tregerman R. Examining the relationship between hospital ownership and population health efforts. J Health Organ Manag. 2018 Nov 19;32(8):934-942. https://doi.org/10.1108/JHOM-02-20180042.

10. Feldman N. Hospital union wants city to rezone Hahnemann property so it can't be flipped. WHYY.org. https://whyy.org/articles/hospital-union-wantscity-to-rezone-hahnemann-property-so-it-cant-be-flipped/. August 2, 2019. Accessed October 10, 2019

11. Brubaker H. New CEO fired at Hahnemann and St. Christopher's Hospital for Children, two months into the job. The Philadelphia Inquirer. https:// www.inquirer.com/business/hahnemann-st-christophers-hospital-ceo-turnover-20190308.html. March 8, 2019. Accessed October 10, 2019

12. Rush M. Hahnemann University Hospital's inner turmoil: A timeline of changes, layoffs, and closing. The Philadelphia Inquirer. https://www.inquirer.com/ business/health/hahnemann-university-hospital-closing-timeline-20190626. html. July 1, 2019. Accessed October 10, 2019.

13. Brubaker H. Drexel sues to block threatened closure of Hahnemann University Hospital. The Philadelphia Inquirer. https://www.inquirer.com/business/ hahnemann-hospital-drexel-freedman-closure-20190624.html. June 24, 2019. Accessed October 10, 2019.

14. Fernandez B, Dunn C. Hahnemann officially closes emergency room to critically ill. Nurses' union says the hospital lacks basic supplies. The Philadelphia Inquirer. https://www.inquirer.com/news/hahnemann-hospital-emergency-room-closing-turmoil-20190629.html. June 29, 2019. Accessed October 10, 2019.

15. Bate D. Bill to prevent sudden hospital closures (like Hahnemann) moves along in City Council. WHYY.org. https://whyy.org/articles/bill-to-preventsudden-hospital-closures-like-hahnemann-moves-along-in-city-council/, November 20, 2019. Accessed October 10, 2019

16. Aizenberg DJ and Logio LS. The Graduate Medical Education (GME) gold rush: GME slots and funding as a financial asset. Acad Med. 2019. https:// doi.org/10.1097/ACM.0000000000003133.

17. Feldman N. Judge puts freeze on sale of Hahnemann residency program - for now. WHYY.org. https://whyy.org/articles/judge-puts-freeze-on-saleof-hahnemann-residency-program-for-now/. September 16, 2019. Accessed October 11, 2019.

18. Pennsylvania Governor's Office Press Release: Governor Wolf, Mayor Kenney Joint Statement on Hahnemann University Hospital. https://www. governor.pa.gov/newsroom/governor-wolf-mayor-kenney-joint-statement-on-hahnemann-university-hospital. July 11, 2019. Accessed October 18, 2019. 